\title{
RESEARCH
}

Open Access

\section{Biochemical response to cryothermal and radiofrequency exposure of the human myocardium at surgical ablation of atrial fibrillation: a randomized controlled trial}

Gabriella Boano ${ }^{1}$, Meriam Åström Aneq ${ }^{2}$, Giannis Spyrou ${ }^{3}$, Helena Enocsson ${ }^{4}$, Emmanouil Charitakis ${ }^{5}$ and Farkas Vánky ${ }^{1 *}$ (D)

\begin{abstract}
Background: Surgical cryothermia and radiofrequency (RF) ablations for atrial fibrillation (AF) seem to result in similar sinus rhythm restoration, but the biochemical consequences of the two methods are unclear. We aimed to compare the biochemical responses to the two ablative methods in concomitant mitral valve surgery (MVS).

Methods: Sixty mitral valve surgery patients with AF were prospectively included. Forty-one patients planned for ablation were randomized to cryothermia $(n=20)$ or radiofrequency $(n=21)$ ablation and 19 served as controls. Markers for myocardial injury, inflammation, cell stress, apoptosis, and heart failure were analyzed pre- and postoperatively at different time points.

Results: Troponin T and creatine kinase isoenzyme MB (CK-MB) peak levels were significantly higher in the cryothermia group compared with the RF group $(12,805$ [6140-15,700] vs. 2790 [1880-4180] ng/L; $P=0.002$ and 271 [217-357] vs. 79 [66-93] $\mu \mathrm{g} / \mathrm{L} ; P<0.001$, respectively). Both groups had significantly higher levels than the noablation group. There were no group differences in C-reactive protein (CRP) and $\mathrm{N}$-terminal pro-B-type natriuretic peptide (NT-proBNP), but there were correlations between pre- and postoperative levels of both CRP $\left(r_{s}=0.41, P=\right.$ $0.001)$ and NT-proBNP $\left(r_{s}=0.48, P<0.001\right)$. Protease-activated receptor 1 (PAR-1) and heat shock protein 27 (HSP27) were significantly increased in the cryoablation group.
\end{abstract}

Conclusions: Cryoablation results in a larger myocardial injury and possibly more elevated apoptotic activity and cell stress compared with the RF technique. The type of ablation device did not have any significant influence on the postoperative inflammatory response nor on the early postoperative levels of NT-proBNP.

Trial registration: DOl:https://doi.org/10.1186/ISRCTN14454361. Registered 16 November 2014 - Retrospectively registered, http://www.isrctn.com/ISRCTN14454361

Keywords: Atrial fibrillation, Mitral valve surgery, Concomitant surgical ablation, Myocardial injury, Heart failure, Apoptosis, Cell stress, Cryoablation, Radiofrequency

\footnotetext{
* Correspondence: farkas.vanky@regionostergotland.se

'Department of Health, Medicine and Caring Sciences, Linköping University,

Department of Thoracic and Vascular Surgery in Östergötland, Linköping,

Sweden

Full list of author information is available at the end of the article
}

(c) The Author(s). 2020 Open Access This article is licensed under a Creative Commons Attribution 4.0 International License, which permits use, sharing, adaptation, distribution and reproduction in any medium or format, as long as you give appropriate credit to the original author(s) and the source, provide a link to the Creative Commons licence, and indicate if changes were made. The images or other third party material in this article are included in the article's Creative Commons licence, unless indicated otherwise in a credit line to the material. If material is not included in the article's Creative Commons licence and your intended use is not permitted by statutory regulation or exceeds the permitted use, you will need to obtain permission directly from the copyright holder. To view a copy of this licence, visit http://creativecommons.org/licenses/by/4.0/. 


\section{Background}

Surgical treatment for atrial fibrillation (AF) consists of a well-defined set of atrial lesions in order to electrically isolate trigger areas and block reentry loops. This was first achieved with the cut-and-sew method, which is somewhat more demanding and time-consuming than the newer methods that create scars using thermal devices [1]. The thermal methods are mostly used along with other cardiac surgery to treat AF [2]. The two recommended methods are cryothermal and bipolar radiofrequency (RF) as they have shown similar results in restoring sinus rhythm in cohort studies [3].

The ablation results in three zones; the central zone of the injury, which is in immediate connection to the probe application, a transitional zone that is either undergoing apoptosis or recovering from reversible damage, and the surrounding tissue that is unaffected by ablation [4]. RF energy produces heat at the interface between the probe and the tissue, while cryoablation uses cold injury to create cellular damage. Two of the main differences between RF and cryoablation are the size of the transitional zone and the tissue response to thermal and cryogenic methods. In RF, the transitional zone is narrower because of the steep decrease of the temperature gradient. The tissue response in the transitional zone in cryoablation is the product of vascular injury and ischemia, apoptosis, and immunomodulation [5]. These responses are much less pronounced with RF ablation [4]. A third difference between the methods is the thermal effect in the central zone. In RF, the central zone undergoes coagulative necrosis at temperatures $\geq 50{ }^{\circ} \mathrm{C}$, which denature most of the intracellular proteins. In cryoablation, fibroblasts and collagen fibers resist freezing injury and the architecture of the tissue, though devitalized, remains as a structure for repair [6].

The effects of these two energy sources in open cardiac surgery on biochemical response are not well known, and the choice of ablation method has so far been based mainly on institutional and personal preferences. Since the mechanisms of tissue damage differ considerably between the two thermal ablation methods, the purpose of this study was to show whether the respective biochemical responses to ablation concomitant with surgery might differ in terms of markers for myocardial injury (Tn-T, CK-MB, ASAT, ALAT) inflammation (CRP, IL-6, IL-18), cell stress and apoptosis (STK4, PAR-1, HSP27, TRAIL R2), and heart failure (NTproBNP). See Table 1.

\section{Methods \\ Study design}

This was a partly randomized, parallel, single-center study comprising patients with AF scheduled for mitral valve surgery. A group of patients ineligible for AF ablation were included as controls and were not subject to randomization.

\section{Study population}

Of 63 consecutive patients, 3 declined participation. Sixty patients with preoperative AF scheduled for mitral

Table 1 Inflammatory, cell stress and apoptosis specific proteins included in the CVD II panel and used in the study

Interleukin-6 (IL-6)

Interleukin-18 (IL-18)

Serine/threonine-protein Kinase 4 (STK4)

Protease-activated receptor 1 (PAR-1)

Heat shock protein 27 (HSP27)

TNF-related apoptosis inducing ligandreceptor 2 (TRAIL-R2)
IL-6 is a cytokine involved in the acute phase response to tissue injury or to an inflammatory stimulus. It acts both locally and systemically and it has its peak concentration a few hours after the end of ECC and gradually decreases within the following $24 \mathrm{~h}[7]$.

IL-18 has a central role in the inflammatory cascade and it is widely expressed by monocytes/ macrophages. High circulating levels have been associated with cardiovascular diseases, ranging from coronary artery disease to heart failure. In particular, a strong association between increased IL-18 levels and atrial fibrillation has been seen [8].

STK4, also known as MST1, is a cytoplasmic kinase. It is a critical component of the Hippo pathway and a key regulator of organ size and regeneration. It acts by inducing autophagy [9], apoptosis and inhibition of cell proliferation. Recently it was shown that STK4 plays an important role in regulating stress response and apoptosis in myocardial injury [10].

PAR-1 is a G-protein coupled receptor, activated by the coagulation protease thrombin, as well as other proteases. In the heart, it is expressed by cardiomyocytes and cardiac fibroblasts. PAR-1 plays an important role in cardiac remodeling after myocardial infarction. Elevated PAR-1 expression in human heart failure contributes to pathological cardiac remodeling (cardiac fibrosis) and hypertrophy [11].

Heat shock proteins are a ubiquitous family of chaperones. They represent the key players within cellular stress responses by stabilizing protein folding of newly synthesized proteins. With a molecular weight of 27 kDa in humans, HSP27 has a dual role, depending on its intracellular or extracellular location [12]. The intracellular overexpression protects cardiac myocytes against ischemic injury. When located in the extracellular spaces HSP27 contributes to the mechanism underlying post ischemic myocardial inflammatory response and cardiac functional injury [13, 14].

TRAIL-R2 is a cell surface receptor for TNF-related apoptosis- inducing ligand with the capacity to induce apoptotic signaling cascades leading to cell death High TRAIL-R2 levels were recently shown to be a predictor of long term mortality in patients with acute myocardial infarction [15]. 
valve surgery were enrolled consecutively between Sept 2013 and October 2015 at Linkoping University Hospital. Patients judged to benefit from AF ablation were randomly assigned, in a 1:1 ratio in blocks of 10 , to undergo concomitant AF ablation with either a cryodevice (cryo group, $n=20$ ) or RF device (RF group, $n=21$ ). Patients with no AF symptoms, and those for whom additional aortic cross clamp time and thereby prolonged ischemia was regarded as too hazardous, underwent mitral valve surgery without AF ablation (no-maze group, $n=19$ ). The decision to ablate or not was made before enrollment by a group of experts in arrhythmia, consisting of cardiologists and cardiac surgeons. The study was approved by the Regional Ethical Review Board (2012/371-31) and patients were recruited after written, informed consent by the surgeon the day before surgery. This study is the first part of the registered clinical trial: DOI https://doi.org/10.1186/ISRCTN14454361.

\section{Ablation methods}

For cryoablation, the argon powered Cardioblate CryoFlex Surgical Ablation Probe (Medtronic Inc., Minneapolis, MN) was used. The probe was applied for $120 \mathrm{~s}$ and the temperature fell rapidly (Joule-Thompson effect) to between $-130{ }^{\circ} \mathrm{C}$ and $-150^{\circ} \mathrm{C}$ at each ablation line. The left atrial lesions consisted of three lines for the left atrium and three for the right atrial wall and followed the Cox IV pattern [16-18]. All but the intercaval lesions were created during cardioplegic arrest. For RF ablation, the Cardioblate BP2 Irrigated Bipolar Surgical Ablation System (Medtronic Inc., Minneapolis, MN) was used. This system uses irrigation and impedance-based power adjustments to reach tissue temperatures between $50^{\circ} \mathrm{C}$ and $80^{\circ} \mathrm{C}$ during ablation, according to the manufacturer. Each line was subject to at least three complete ablation periods. During RF ablation, the right and the left pulmonary vein orifices were isolated pairwise and epicardially on bypass [19], but before cardioplegia was given. During cardioplegic arrest, the left atrial ablation was completed according to the Cox IV pattern [20].

\section{Procedures}

All patients were operated on by the same surgeon. Myocardial arrest was induced and maintained with combined antegrade and retrograde cold blood cardioplegia. Biatrial lesions were induced, during cardioplegia arrest, in all ablation patients except for one in the cryo group and three in the RF group, who underwent only left-sided ablations. The left atrial appendage was stapled and excised with an Endo GIA Reinforced device (Medtronic Inc., Minneapolis, MN). The surgical procedures and patient characteristics are summarized in Table 1.

\section{Blood sampling and biochemical analyses}

Blood was collected preoperatively on the day before surgery (Pre), at the end of surgery (T0), $3 \mathrm{~h}$ (T3), $20 \mathrm{~h}$ (T20), and 3 days (D3) postoperatively. Troponin T ( TnT) was analyzed at Pre, T0, T3, T20, and D3. Creatine kinase isoenzyme $\mathrm{MB}(\mathrm{CK}-\mathrm{MB})$ and aspartate aminotransferase (ASAT) were analyzed at Pre, T0, T3, and T20. C-reactive protein (CRP) and alanine aminotransferase (ALAT) were analyzed at Pre and T20. NTproBNP was analyzed at Pre, T20, and D3.

CK-MB, Tn-T, and NT-proBNP was analyzed in serum samples using an electrochemiluminescence immunoassay. A particle-enhanced immunoturbidimetric assay was used for CRP measurement in plasma samples preoperatively and postoperatively, and pyridoxal phosphate activation for ASAT and ALAT. The cobas c701 and e602 analyzers (Roche Diagnostics GmbH, Mannheim, Germany) were used. Additional biomarkers were analyzed using the Proseek Multiplex CVD II panel (Olink Proteomics, Uppsala, Sweden), simultaneously measuring 92 proteins. This analysis provides very high sensitivity and specificity as it is performed using a matched pair of antibodies coupled to unique oligonucleotides and measured by quantitative real-time PCR. For this study, blood samples from Pre, T0, T3, and T20 were fractionated and plasma was stored at $-70{ }^{\circ} \mathrm{C}$ before being sent to the Clinical Biomarkers National Facility (Science for Life Laboratory, Uppsala) for analysis.

In this survey, interleukins 6 and 18 (IL-6 and IL-18) were selected as markers for inflammation, and serine/ threonine-protein kinase 4 (STK4) also known as MST1, proteinase activated receptor 1 (PAR-1), heat shock 27 $\mathrm{kDa}$ protein (HSP27), and TNF-related apoptosisinducing ligand receptor 2 (TRAIL-R2) were selected as markers of cellular stress/apoptosis. Data from the Proseek Multiplex CVD II panel are presented as the differences in normalized protein expression (NPX) between preoperative levels and $\mathrm{T} 0, \mathrm{~T} 3$, and $\mathrm{T} 20(\Delta \mathrm{T} 0, \Delta \mathrm{T} 3$, and $\Delta \mathrm{T} 20)$. The log-2 transformed data were linearized before calculating differences from preoperative values. Data from $3.8 \%$ of the samples were excluded from analysis due to assay failure or failure to pass quality control.

\section{Statistical methods}

Sample-size calculation was based on the difference in markers for myocardial injury in pilot patients with and without concomitant cryoablation. The number of patients needed in each group to detect such a large difference was 3 . We included 60 patients in the study to ensure at least 17 patients each in the cryoablation and RF ablation groups, enough to detect an effect size of 1 . Continuous variables are presented as medians [25th to 
75th percentile] and categorical variables as counts (percentages). For comparisons of the three groups, the Kruskal-Wallis test was used, taking into account multiple comparisons of mean ranks for all groups' $P$ values, and post-hoc comparisons of mean ranks of all pairs of groups when the Kruskal-Wallis test showed significance. The Spearman rank test was used for correlations between two variables. Multivariable linear regression models were used to find the factors influencing myocardial injury. The Tn-T and CK-MB at $3 \mathrm{~h}$ postoperatively and ASAT at $20 \mathrm{~h}$ postoperatively were chosen as dependent factors and log-10 transformed to align with the assumption of Gaussian distribution. Study groups, age, gender, cross clamp time (CCT), coronary artery disease, and the extent of ablation were tested as predictors. The models were fit using an enter method. Multicollinearity was found between the study groups and the extent of ablation. Therefore, the extent of ablation was excluded from the models. For comparison of the markers of myocardial injury between the three study groups over time-repeated measurements, analysis of variance was used. A $P$ value $<0.05$ was considered statistically significant. Statistical analyses were conducted with Statistica 10.0 (StatSoft Inc., Tulsa, OK) and SPSS 22.0 (SPSS, Inc., Chicago, IL).

\section{Results}

There were no significant differences between the cryo and the RF groups with regard to preoperative, operative, and postoperative characteristics (Table 2). Patients in the No-maze group were older compared with the patients in the intervention groups, but did not differ markedly in other preoperative comorbidities.

\section{Markers of myocardial injury and their thermal stability}

The highest levels of Tn-T, CK-MB, and ASAT were measured $3 \mathrm{~h}$ after surgery (Table 3 ). There were, however, significant differences in $\mathrm{Tn}-\mathrm{T}$ and $\mathrm{CK}-\mathrm{MB}$ between all three groups, with the cryo group having the highest levels. There was no significant difference in ASAT between the cryo and the RF groups but both had higher levels than the no-maze group (Fig. 1). Correcting for the patients with only left atrial ablation lines did not influence the median levels of the markers for myocardial injury or the differences between groups. The AF ablation and method explained a large proportion of variance in the peak levels of markers for myocardial injury. Other explanatory variables were CCT, absence of coronary artery disease, and age (Table 4).

We conducted in vitro experiments to evaluate if locally increased temperatures during RF procedures might create a detection bias because of denaturation. To analyze thermal effects on TnT, CK-MB, ASAT, and ALAT detection, plasma samples from 10 patients were heated to $37^{\circ} \mathrm{C}, 56{ }^{\circ} \mathrm{C}, 65^{\circ} \mathrm{C}$, and $80^{\circ} \mathrm{C}$ for 3 min and the results were compared with a non-heated sample (Fig. 2). Detection of Tn-T and ASAT was unaffected by temperature while ALAT detection was partially affected at $65{ }^{\circ} \mathrm{C}$ (Fig. 2). CK-MB levels were temperature dependent and decreased dramatically even at $56{ }^{\circ} \mathrm{C}$, suggesting that the lower levels measured during RF are most probably due to protein denaturation.

Multivariable linear regression models showing the factors with significant influence on myocardial injury. The Tn-T and CK-MB at $3 \mathrm{~h}$ postoperatively and ASAT at $20 \mathrm{~h}$ postoperatively were chosen as dependent factors and $\log 10$ transformed to align with the assumption of Gaussian distribution. The models were fit by an enter method. The extent of ablation was excluded from the models due to multicollinearity with the study groups. 95\%CI: 95\% confidence interval, RF: radio frequency, Tn-T: troponin T, CK-MB: creatine kinase isoenzyme MB, ASAT: aspartate aminotransferase, T3: $3 \mathrm{~h}$ postoperatively, T20: $20 \mathrm{~h}$ postoperatively.

\section{Markers of inflammation (CRP, IL-6, and IL-18)}

There were no significant differences in postoperative CRP levels between the three groups (Table 2). Both preoperative CRP and CCT correlated with CRP $20 \mathrm{~h}$ postoperatively $\left(r_{\mathrm{s}}=0.41, P=0.001\right.$ and $r_{\mathrm{s}}=0.22, P=$ 0.01 , respectively) in the whole study population. No significant differences between the three groups of patients regarding the pro-inflammatory cytokines IL-6 and IL18 were found at any time point (Table 3 ).

\section{Markers of cell stress and apoptosis (PAR-1, HSP27, STK4, TRAIL R2)}

PAR-1 elevation from preoperation to $3 \mathrm{~h}$ after surgery $(\Delta \mathrm{T} 3)$ was significantly higher in the cryo compared with the RF group $(P=0.002)$ (Table 3 , Fig. 3). $\Delta \mathrm{T} 3 \mathrm{HSP} 27$ levels also differed significantly between the three study groups $(P=0.007)$ and in pairwise comparison, increased levels were found in the cryo compared with the RF group $(P=0.002)$ and compared with the no-maze group $(P=0.001)$, but there was no difference between RF and No-maze patients (Table 3, Fig. 4). At $\Delta \mathrm{T} 3$, the decrease in STK4 had a tendency to be more pronounced in the $\mathrm{RF}$ group compared with the cryo group, although not statistically significant $(P=0.06)$. TRAIL-R2 did not show any significant differences between the study groups.

\section{Marker of heart failure (NT-proBNP)}

There were no significant differences in postoperative NT-proBNP levels between the three groups (Table 3). Preoperative NT-proBNP correlated with NT-proBNP at $20 \mathrm{~h}$ and 3 days postoperatively $\left(r_{\mathrm{s}}=0.48, P<0.001\right.$ and $r_{\mathrm{s}}=0.58, \quad P<0.001$, respectively) but there were no 
Table 2 Pre-, per- and postoperative data of the three study groups

\begin{tabular}{|c|c|c|c|c|c|c|c|}
\hline Variables & $\begin{array}{l}\text { Cryothermia } \\
(n=20)\end{array}$ & $\operatorname{RF}(n=21)$ & $\begin{array}{l}p \text { Value } \\
\text { Cryo vs. } \\
\text { RF }\end{array}$ & $\begin{array}{l}\text { No-maze } \\
(n=19)\end{array}$ & $\begin{array}{l}p \text { Value } \\
\text { No-maze } \\
\text { vs. Cryo }\end{array}$ & $\begin{array}{l}p \text { Value } \\
\text { No-maze } \\
\text { vs. RF }\end{array}$ & $p$ Value \\
\hline \multicolumn{8}{|l|}{ Preoperative data } \\
\hline Female & $5(25 \%)$ & $12(57 \%)$ & & $7(37 \%)$ & & & 0.11 \\
\hline Age (years) & $71[65-74]$ & $72[66-74]$ & 1.0 & 77 [73-78] & 0.02 & 0.006 & 0.004 \\
\hline COPD & $4(20 \%)$ & $4(19 \%)$ & & $2(10.5 \%)$ & & & 0.69 \\
\hline NYHA III or IV & $17(85 \%)$ & $14(67 \%)$ & & 15 (79\%) & & & 0.37 \\
\hline Congestive heart failure & $12(60 \%)$ & $13(62 \%)$ & & $16(84 \%)$ & & & 0.20 \\
\hline Euroscore II & $5.1[3.2-6.7]$ & $5.4[4.3-7.0]$ & & $4.7[3.2-7.4]$ & & & 0.88 \\
\hline Body mass index $\left(\mathrm{kg} / \mathrm{m}^{2}\right)$ & 25 [24-28] & 25 [24-29] & & 26 [23-29] & & & 0.80 \\
\hline Non paroxysmal AF & $15(75 \%)$ & $15(71 \%)$ & & $13(68 \%)$ & & & 0.90 \\
\hline LVEF $<50 \%$ & $5(26 \%)$ & $6(29 \%)$ & & $5(26 \%)$ & & & 0.97 \\
\hline Left atrium area $\left(\mathrm{cm}^{2}\right)$ & 35 [30-40] & $32[30-36]$ & & $32[25-40]$ & & & 0.35 \\
\hline TAPSE (mm) & 19 [17-22] & $16[16-21]$ & & 15 [13-20] & & & 0.17 \\
\hline Right atrium area $\left(\mathrm{cm}^{2}\right)$ & $28[26-31]$ & 25 [22-30] & & $28[21-31]$ & & & 0.29 \\
\hline Pulmonary artery pressure $(\mathrm{mmHg})$ & 38 [30-50] & $43[32-50]$ & & $50[35-60]$ & & & 0.10 \\
\hline \multicolumn{8}{|l|}{ Operative data } \\
\hline Surgery time (min) & $253[235-306]$ & $253[225-286]$ & & $220[195-250]$ & & & 0.06 \\
\hline Extracorporeal circulation (min) & 158 [147-205] & 163 [148-193] & 1.00 & $131[116-178]$ & 0.03 & 0.03 & 0.01 \\
\hline Cross clamp time (min) & 106 [101-129] & 95 [86-120] & 0.31 & 85 [77-100] & 0.005 & 0.36 & 0.007 \\
\hline Mitral valve replacement & $2(10 \%)$ & $5(24 \%)$ & & $5(26 \%)$ & & & 0.39 \\
\hline Tricuspid valve surgery & $15(75 \%)$ & $15(71 \%)$ & & $12(63 \%)$ & & & 0.72 \\
\hline Coronary surgery & $5(25 \%)$ & $6(29 \%)$ & & $7(37 \%)$ & & & 0.72 \\
\hline Aortic valve replacement & $2(10 \%)$ & $3(14 \%)$ & & $2(11 \%)$ & & & 0.90 \\
\hline Aortic surgery & $1(5 \%)$ & 0 & & $1(5 \%)$ & & & 0.58 \\
\hline Left atrium appendage resection & $13(65 \%)$ & $20(95 \%)$ & 0.29 & $6(32 \%)$ & 0.22 & 0.002 & $<0.001$ \\
\hline Inotropic drugs at weaning & $18(90 \%)$ & $14(67 \%)$ & 0.60 & $8(42 \%)$ & 0.03 & 0.55 & 0.007 \\
\hline LVAD at weaning & $1(5 \%)$ & 0 & & 0 & & & 0.37 \\
\hline \multicolumn{8}{|l|}{ Postoperative outcome } \\
\hline Time on ventilator (h) & $2.6[1.8-6.9]$ & $4.3[3.4-11.7]$ & & $7.3[3.5-10.8]$ & & & 0.08 \\
\hline Sinus rhythm at discharge & $13(65 \%)$ & $11(52 \%)$ & 1.00 & $1(5 \%)$ & 0.004 & 0.03 & $<0.001$ \\
\hline 30-day mortality & $1(5 \%)$ & 0 & & 0 & & & 0.37 \\
\hline Stroke, permanent & 0 & $1(5 \%)$ & & 0 & & & 0.40 \\
\hline Dialysis & $1(5 \%)$ & $1(5 \%)$ & & $2(11 \%)$ & & & 0.72 \\
\hline
\end{tabular}

Data are presented as the median [25th to 75th percentile] or count (percentage). ${ }^{*}$ Post-hoc comparisons of mean ranks of pairs of groups. ${ }^{* *}$ Multiple comparisons of mean ranks for all groups, Kruskal-Wallis test. RF Radio frequency, COPD Chronic obstructive pulmonary disease, NYHA New York Heart Association class, AF Atrial fibrillation, LVEF Left ventricular ejection fraction, TAPSE Tricuspid annular plane systolic excursion, LVAD Left ventricular assist device

significant correlations between CCT and postoperative NT-proBNP levels $\left(r_{\mathrm{s}}=0.11, P=0.4\right.$ and $r_{\mathrm{s}}=-0.14, P=$ 0.3 , respectively).

\section{Discussion}

To our knowledge, this is the first randomized prospective study in cardiac surgery comparing the biochemical responses to the two most common methods used to perform ablation concomitant with surgery. We were able to show significantly higher levels of myocardial injury biomarkers, and more elevated apoptotic activity and cell stress, in cryoablation compared with the RF technique.

\section{Myocardial injury}

The high levels of CK-MB and Tn-T after both surgical ablative procedures reflect the device-induced atrial myocardial injury. The concentrations of both markers in patients that underwent cryoablation had greater increases at T0, T3, and T20 compared with those who 
Table 3 Biochemical markers

\begin{tabular}{|c|c|c|c|c|c|c|c|}
\hline Variables & $\begin{array}{l}\text { Cryothermia } \\
(n=20)\end{array}$ & $\operatorname{RF}(n=21)$ & $\begin{array}{l}p \text { Value } \\
\text { Cryo vs. RF }\end{array}$ & $\begin{array}{l}\text { No-maze } \\
(n=19)\end{array}$ & $\begin{array}{l}p \text { Value } \\
\text { No-maze } \\
\text { vs. Cryo }\end{array}$ & $\begin{array}{l}p \text { Value* } \\
\text { No-maze } \\
\text { vs. RF }\end{array}$ & $p$ Value \\
\hline \multicolumn{8}{|l|}{ Tn-T (ng/L) } \\
\hline Preoperative & $12.5[8.5-17]$ & 12 [9-16] & & 15 [11-17] & & & 0.53 \\
\hline TO & $8145[5095-14,440]$ & 2140 [1900-3290] & 0.002 & 709 [517-786] & $<0.001$ & 0.002 & $<0.001$ \\
\hline T3 & $12,805[6140-15,700]$ & 2790 [1880-4180] & 0.002 & 999 [683-1420] & $<0.001$ & 0.002 & $<0.001$ \\
\hline $\mathrm{T} 20$ & 3400 [2785-4900] & 1980 [1640-2530] & 0.01 & 798 [565-929] & $<0.001$ & 0.001 & $<0.001$ \\
\hline Postoperative day 3 & 2095 [1645-3275] & 1200 [1030-1670] & 0.005 & $576[437-754]$ & $<0.001$ & 0.01 & $<0.001$ \\
\hline \multicolumn{8}{|l|}{ CK-MB ( $\mu \mathrm{g} / \mathrm{L})$} \\
\hline Preoperative & $2[1.5-2.5]$ & $2[1-3]$ & & $2[2-3]$ & & & 0.99 \\
\hline T0 & 269 [243-352] & $68[62-81]$ & $<0.001$ & 47 [34-59] & $<0.001$ & 0.06 & $<0.001$ \\
\hline T3 & 271 [217-357] & 79 [66-93] & $<0.001$ & $48[32-71]$ & $<0.001$ & 0.09 & $<0.001$ \\
\hline T20 & 107 [69-132] & $53[42-57]$ & 0.005 & 29 [18-43] & $<0.001$ & 0.02 & $<0.001$ \\
\hline \multicolumn{8}{|l|}{ ASAT $(\mu \mathrm{g} / \mathrm{L})$} \\
\hline Preoperative & $0.5[0.4-0.5]$ & $0.5[0.4-0.5]$ & & $0.5[0.4-0.6]$ & & & 0.58 \\
\hline TO & $2.5[1.8-3.9]$ & $2.4[1.8-3.4]$ & 1.0 & $1.2[0.9-1.5]$ & $<0.001$ & 0.001 & $<0.001$ \\
\hline $\mathrm{T} 3$ & $3.3[2.5-5.9]$ & $2.9[2-4.1]$ & 0.55 & $1.3[1.1-1.7]$ & $<0.001$ & $<0.001$ & $<0.001$ \\
\hline $\mathrm{T} 20$ & $3.3[2.5-3.8]$ & $2.2[2-2.6]$ & 0.006 & $1.3[1.0-1.6]$ & $<0.001$ & 0.01 & $<0.001$ \\
\hline \multicolumn{8}{|l|}{ ALAT $(\mu \mathrm{g} / \mathrm{L})$} \\
\hline Preoperative & $0.4[0.3-0.5]$ & $0.4[0.4-0.5]$ & & $0.4[0.3-0.5]$ & & & 0.64 \\
\hline $\mathrm{T} 20$ & $0.5[0.4-0.7]$ & $0.5[0.4-0.6]$ & & $0.5[0.3-0.6]$ & & & 0.16 \\
\hline \multicolumn{8}{|l|}{ CRP (mg/L) } \\
\hline Preoperative & $0.9[0.4-1.9]$ & $1.7[0.7-3.9]$ & 0.40 & $2.8[1.5-7.2]$ & 0.01 & 0.38 & 0.01 \\
\hline T20 & 77 [63-86] & 75 [52-104] & & 77 [60-87] & & & 0.89 \\
\hline \multicolumn{8}{|l|}{ IL-6 (NPX) } \\
\hline$\Delta$ T0-Preoperative & 300 [221-510] & 185 [121-365] & & 193 [137-386] & & & 0.23 \\
\hline$\Delta \mathrm{T} 3$-Preoperative & 223 [159-333] & 141 [106-279] & & 206 [112-317] & & & 0.20 \\
\hline$\Delta \mathrm{T} 20$-Preoperative & 150 [82-332] & 120 [85-193] & & 222 [135-433] & & & 0.09 \\
\hline \multicolumn{8}{|l|}{ IL-18 (NPX) } \\
\hline$\Delta$ T0-Preoperative & $-38[-65--19]$ & $-37[-64-6]$ & & $-50[-60--23]$ & & & 0.87 \\
\hline$\Delta \mathrm{T} 3$-Preoperative & $-5[-34-9]$ & $-38[-45--3]$ & & $-10[-29--3]$ & & & 0.32 \\
\hline$\Delta T 20$-Preoperative & $-11[-33--1]$ & $-12[-34-7]$ & & $-28[-64-3]$ & & & 0.47 \\
\hline \multicolumn{8}{|l|}{ STK4 (MST1) (NPX) } \\
\hline$\Delta$ T0-Preoperative & $-4.0[-7.1--0.1]$ & $-2.6[-12.0--1.0]$ & & $-5.0[-8.6--3.1]$ & & & 0.5 \\
\hline$\Delta \mathrm{T} 3$-Preoperative & $-3.1[-5.9--0.7]$ & $-6.9[-10.2--2.9]$ & & $-5.3[-7.0--1.7]$ & & & 0.06 \\
\hline$\Delta T 20$-Preoperative & $-6.6[-8.5--2.4]$ & $-6.1[-11.2--3.1]$ & & $-8.1[-10.5--3.8]$ & & & 0.6 \\
\hline \multicolumn{8}{|l|}{ PAR-1 (NPX) } \\
\hline$\Delta$ T0-Preoperative & $-5.0[-10.3-17.0]$ & $2.2[-15.6-16.2]$ & & $-7.3[-18.6-5.6]$ & & & 0.3 \\
\hline$\Delta \mathrm{T} 3$-Preoperative & $7.8[0.1-17.6]$ & $-9.8[-19.3-0.1]$ & 0.002 & $-5.0[-14.6-4.8]$ & 0.08 & 0.9 & 0.003 \\
\hline$\Delta \mathrm{T} 20$-Preoperative & $-8.1[-18.8-8.0]$ & $-17.0[-21.8-4.0]$ & & $-15.7[-26.8--9.4]$ & & & 0.3 \\
\hline \multicolumn{8}{|l|}{ HSP27 (NPX) } \\
\hline$\Delta$ T0-Preoperative & 259 [98-310] & $151[-35-330]$ & 0.6 & $106[-133-174]$ & 0.03 & 0.6 & 0.04 \\
\hline$\Delta \mathrm{T} 3$-Preoperative & 196 [129-278] & $42[-181-156]$ & 0.02 & $-26[-115-98]$ & 0.001 & 1.0 & 0.007 \\
\hline$\Delta \mathrm{T} 20$-Preoperative & $-40[-204-81]$ & $-87[-301-80]$ & & $-138[-271--23]$ & & & 0.3 \\
\hline
\end{tabular}


Table 3 Biochemical markers (Continued)

\begin{tabular}{|c|c|c|c|c|c|c|c|}
\hline Variables & $\begin{array}{l}\text { Cryothermia } \\
(n=20)\end{array}$ & $\operatorname{RF}(n=21)$ & $\begin{array}{l}p \text { Value } \\
\text { Cryo vs. RF }\end{array}$ & $\begin{array}{l}\text { No-maze } \\
(n=19)\end{array}$ & $\begin{array}{l}p \text { Value } \\
\text { No-maze } \\
\text { vs. Cryo }\end{array}$ & $\begin{array}{l}p \text { Value* } \\
\text { No-maze } \\
\text { vs. RF }\end{array}$ & $p$ Value \\
\hline \multicolumn{8}{|l|}{ TRAIL-R2 (NPX) } \\
\hline$\Delta$ T0-Preoperative & 6.6 [2.7-13.7] & $8.7[7.0-21]$ & & $4.2[2.5-11.3]$ & & & 0.2 \\
\hline$\Delta T 3$-Preoperative & 27 [21-38] & 23 [17-31] & & 20 [17-37] & & & 0.1 \\
\hline$\Delta T 20$-Preoperative & 25 [19-33] & 25 [15-40] & & 25 [16-40] & & & 0.9 \\
\hline \multicolumn{8}{|l|}{ NT-proBNP (ng/L) } \\
\hline Preoperative & 1250 [730-1945] & 1380 [950-1910] & & 1620 [1220-3120] & & & 0.65 \\
\hline T20 & $5290[3295-10,615]$ & 5470 [3060-9250] & & 3730 [2750-5810] & & & 0.48 \\
\hline Postoperative day 3 & 6105 [4300-9185] & $6000[3990-11,200]$ & & $5430[3660-14,000]$ & & & 0.99 \\
\hline
\end{tabular}

underwent RF ablation and with the control group. This initial postoperative biomarker leakage is a confounding factor in the early detection of possible ventricular damage due to ischemia. In perioperative ischemic myocardial injury, CK-MB and Tn-T peaks are seen respectively $20 \mathrm{~h}$ postoperatively and at $40 \mathrm{~h}$ [21]. We could show that, with ablation, CK-MB and Tn-T leakage have their peaks immediately after the procedure and $3 \mathrm{~h}$ later, respectively. We could therefore deduce in line with catheter ablation studies [22-25] that marked elevations of TnT and CK-MB measured early postoperatively indicate direct myocyte damage rather than ischemia. Other factors with weak but statistically significant associations with markers for myocardial injury, beside ablation and ablation method, were CCT, age, and the absence of coronary artery disease. An important aspect to consider upon RF ablation is the heat-induced denaturation of the protein creatine kinase. The true myocardial tissue

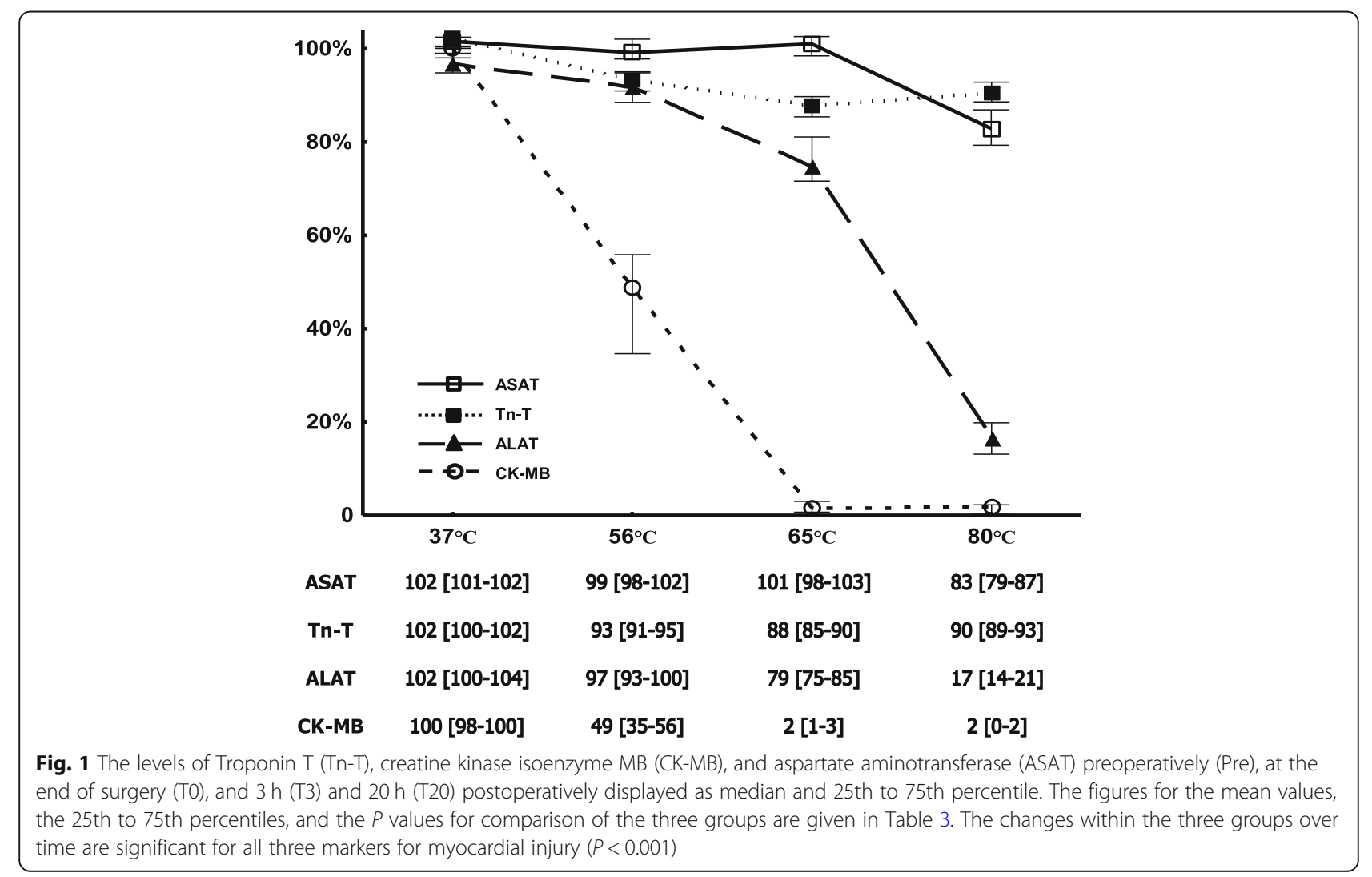


Table 4 Multivariable linear regression models to find factors influencing myocardial injury

\begin{tabular}{|c|c|c|c|}
\hline Variables & $\begin{array}{l}\text { Standardized } \\
\text { coefficient } \beta\end{array}$ & $95 \% \mathrm{Cl}$ & $p$ Value \\
\hline \multicolumn{4}{|l|}{$\begin{array}{l}\text { Dependent variable: } \log 10 \mathrm{Tn}-\mathrm{T} \text { (T3) } \\
\text { Adjusted } \mathrm{R}^{2}=0.79\end{array}$} \\
\hline Patient groups (No-maze $=1, \mathrm{RF}=2, \mathrm{Cryo}=3$ ) & 0.85 & 0.71 to 0.98 & $<0.001$ \\
\hline Coronary artery disease $(\mathrm{no}=0$, yes $=1)$ & -0.18 & -0.32 to -0.05 & 0.007 \\
\hline Age (years) & 0.15 & 0.02 to 0.28 & 0.02 \\
\hline Cross clamp time (min) & 0.15 & 0.01 to 0.29 & 0.04 \\
\hline \multicolumn{4}{|l|}{$\begin{array}{l}\text { Dependent variable: } \log 10 \text { CK-MB (T3) } \\
\text { Adjusted } R^{2}=0.70\end{array}$} \\
\hline Patient groups (No-maze $=1, \mathrm{RF}=2$, Cryo $=3$ ) & 0.84 & 0.70 to 0.98 & $<0.001$ \\
\hline \multicolumn{4}{|l|}{$\begin{array}{l}\text { Dependent variable: } \log 10 \text { ASAT (T20) } \\
\text { Adjusted } R^{2}=0.64\end{array}$} \\
\hline Patient groups (No-maze $=1, \mathrm{RF}=2, \mathrm{Cryo}=3$ ) & 0.66 & 0.49 to 0.83 & $<0.001$ \\
\hline Cross clamp time (min) & 0.26 & 0.08 to 0.44 & 0.005 \\
\hline Coronary artery disease $($ no $=0$, yes $=1)$ & -0.20 & -0.37 to -0.03 & 0.02 \\
\hline
\end{tabular}

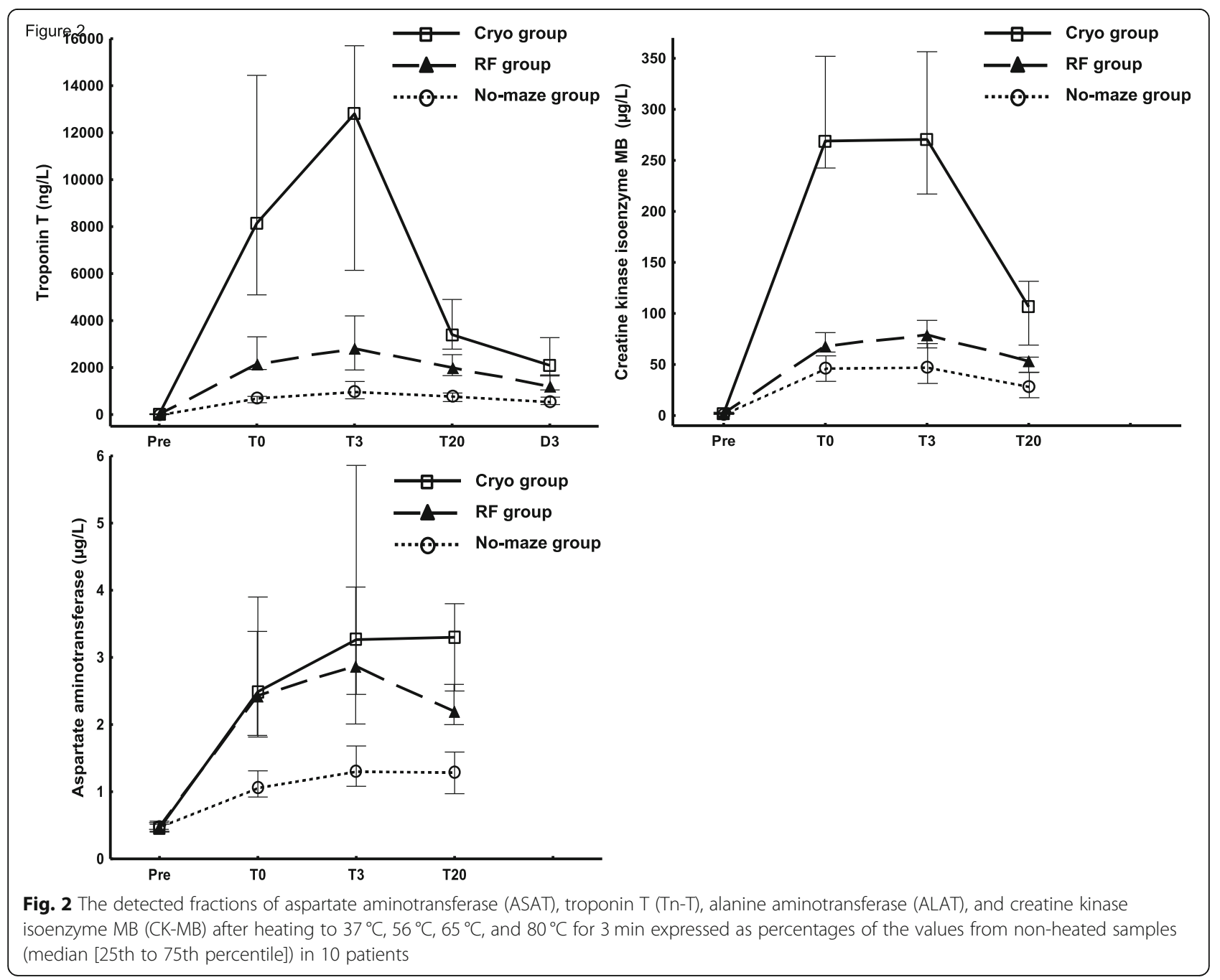




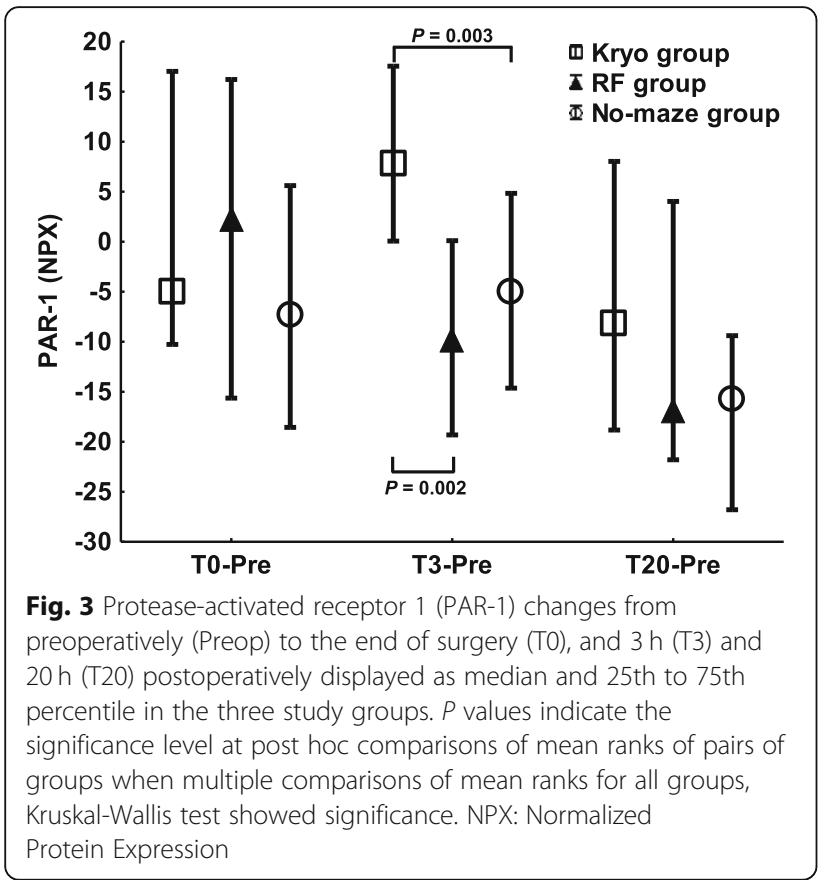

damage caused by heating might be underestimated when measured by CK-MB [26]. The central zone of the $\mathrm{RF}$ lesion reaches temperatures of $>65^{\circ} \mathrm{C}$ and, according to our in vitro experiment and to Haines et al. [27], the immunoassay method used to analyze CK-MB failed to detect heat-denatured CK-MB. This heat-dependent detection bias may explain the comparably modest differences in CK-MB between the RF and No-maze groups, but more importantly it may lead to a falsely large difference in CK-MB between RF and cryoablation [28]. Tn-T

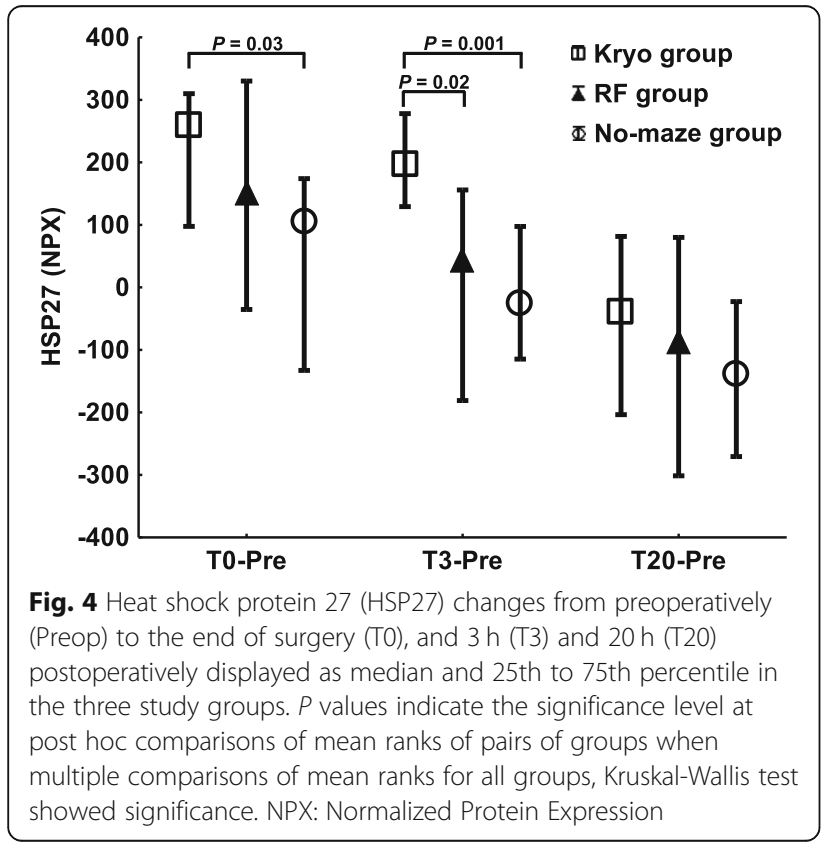

analysis was not as sensitive to thermal denaturation and therefore better reflects the differences in myocardial damage between the three study groups. ASAT was stable at temperatures above $65^{\circ} \mathrm{C}$ and no significant difference was found between the cryo and RF groups. One explanation for this might be that ASAT is less myocardiumspecific compared with CK-MB and Tn-T. This study was not powered to detect differences between cryo- and RF ablation in rhythm outcome. Thus, the larger myocardial injury indicated by the higher levels of cardiac biomarkers at cryoablation did not translate into a significantly better rhythm outcome at discharge compared with RF ablation. Larger randomized studies are warranted to explore possible differences in success rate between the two methods.

\section{Inflammation}

There is increasing evidence that AF is associated with inflammation, and active recruitment of macrophages across the atrial endocardium has been demonstrated in AF patients [29]. When inflammatory active cells are present in the atrial wall, the RF and cryoablation methods may result in different amounts of released bioactive inflammatory agents and thereby different systemic inflammatory responses.

Following ablation, tissue repair is initiated by an immediate infiltration of inflammatory cells (lymphocytes and macrophages) in response to the release of cyto- and chemokines from damaged cells. We know from ablation of tumors that cryoablation induces a notably higher postablative immunogenicity in which proinflammatory cytokines are released in higher quantities compared with other ablative modalities [30, 31]. In catheter ablation studies, cryoablation and RF resulted in comparable increases in inflammatory response markers [23, 32].

In our study, the addition of the ablation therapy did not affect the early inflammatory response. Neither CRP, nor IL-6, nor IL-18 differed significantly in levels between the three groups. The inflammatory response to surgical trauma and the extracorporeal circulation probably overrode the possible inflammatory activation caused by ablation. However, we found a significant correlation between CRP preoperatively and CRP $20 \mathrm{~h}$ after surgery. Hence, a subclinical, preoperative inflammatory activity might predispose patients to a higher postoperative inflammatory response.

\section{Cell stress and apoptosis}

The cornerstone of direct cell injury from freezing is ice crystal formation, which removes water from the cells and leads to the necrosis of the central part of the frozen volume while the peripheral zone shows apoptosis that is thought to arise from mitochondrial damage due to increased bcl-2-associated $\mathrm{X}$ protein (BAX) protein expression and caspase activation [6]. Cells that are not immediately killed by direct cryoablation-induced injury 
may subsequently die by apoptosis. Apoptotic cell death after cryoablation has therefore been shown in the transitional zone where exposure to temperatures that are not immediately lethal results in irrecoverable cellular injury without immediate cell death [33].

We found interesting differences in PAR-1 and HSP27. PAR-1 was significantly decreased in the RF group. A possible explanation for this difference could be the small and more distinct RF ablation lines compared with the larger lesions seen with the cryoprobe. Tissue repair is initiated by an immediate infiltration of inflammatory cells and in the following weeks the necrotic tissue is slowly removed and replaced by a fibrous, collagenous scar [6]. Being involved in the fibrotic process that could lead to cardiac fibrosis, PAR-1 might have a key role in pathologic cardiac remodeling of myocytes after ablative atrial injuries. The late consequences of the size of the atrial injury are still unknown.

At no postoperative time points did STK4 and TRAILR2 differ significantly between the groups. TRAIL initiates intracellular signaling cascade resulting in the apoptotic cell death after binding to its receptors TRAIL-R1 and TRAIL-R2 [34]. In recent years TRAIL-R2 has been shown to have a unique selectivity for triggering apoptosis in tumor cell while leaving normal tissues intact [35]. Its expression is high in cancer cell lines and increased in viral-induced apoptosis [36], but it is not abundant in most normal human cells [37]. TRAIL-R2 seems therefore to have a minor role in myocyte/myocardium apoptosis compared to apoptosis in other tissues. This could be a possible explanation for not seeing a significant difference between the cryothermally induced apoptosis from the RF one. The mechanism of apoptosis in the transitional areas might only partly be TRAIL-R2 mediated.

HPS27 has a dual role depending on its intracellular or extracellular location. Intracellular HSP27 protects against tissue injury (anti-apoptotic property) allowing the cells to survive potentially lethal conditions such as acute coronary syndromes and reperfusion after ischemic clamping during heart by-pass surgery. Increased expression of HSP27 has been shown to provide cardioprotection against hypoxic injury [14]. Extracellular HSP27 is involved in various immunological processes, being a strong immune modulator, and its abundance in serum is a biomarker for ischemic events [12].

In our study, HSP27 elevation at T3 was significantly higher in the cryo compared with the RF and No-maze groups. This could be the result of the rapidly stimulated HSP27 expression and release by cardiomyocytes in response to the larger cryogenic injury. It might also be the effect of the activated transitional and necrotic central zones which, after the thawing phase, release intracellular HSP27 that is still biologically active after cryogenic injury. Heating of the cellular tissue should result in coagulated and, thereby, biologically inactivated proteins. In contrast, the cryoablation device freezes the myocardium, leading to destruction of the cell membranes, but the intra- and extracellular proteins released to the circulation maintain their bioactivity [4].

\section{Postoperative heart failure}

The possible contribution of cryoablation to postoperative heart failure has previously been discussed [38]. The use of inotropes at weaning from extracorporeal circulation was significantly higher in the cryoablation patients compared with the non-ablated patients, but the addition of ablation to mitral valve surgery and the type of energy source did not seem to influence the early postoperative levels of NTproBNP.

\section{Limitations}

The study group size was limited and clinical conclusions cannot, therefore, be based upon the biochemical findings. Larger studies are needed in the future to analyze clinical outcomes in different ablation methods. Only the two ablation groups were randomized. Comparisons between the No-maze group and the two ablation groups should be interpreted cautiously, even though we corrected for some of the differences in the analyses. We think it would have been of interest to analyze more apoptosis-specific proteins than the ones included in the CVD II panel and to follow the cardiac biomarkers up to 4 days postoperatively. The systemic biochemical response to the surgical trauma and to the extracorporeal circulation might obscure the effect of the ablation on the myocardial tissue in this clinical setting. Significant differences between the groups are, however, still relevant.

\section{Conclusions}

Our findings indicate increased myocardial injury when surgical ablation for AF is carried out with a cryogenic compared with an RF device. We also showed that the heat-induced denaturation of creatine kinase caused a detection bias that might lead to underestimation of this injury in case of RF. The addition of ablation to mitral valve surgery and the type of ablation device do not have any significant influence on the postoperative inflammatory response nor on the early postoperative NTproBNP levels.

Higher HSP27 and PAR-1 levels could support the hypothesis that freezing damages tissue by a different intrinsic mechanism than that of RF, in addition to creating a locally wider area of damage to the atrial wall. These results might confirm the importance of apoptosis 
as a mechanism of cell death after cryosurgery especially in the periphery of the previously frozen tissue.

The physiologic significance and clinical implications of the more extensive atrial cellular damage caused by cryoablation are still uncertain and should be investigated in further studies.

\section{Abbreviations}

ALAT: Alanine aminotransferase; ASAT: Aspartate aminotransferase; CKMB: Creatine kinase isoenzyme MB; CRP: C-reactive protein; HSP27: Hheat shock protein 27; IL-6: Interleukin - 6; IL-18: Interleukin-18MVSMitral valve surgery; NPX: Normalized protein expression; NT-proBNP: N-terminal pro-Btype natriuretic peptide; PAR-1: Protease-activated receptor 1; RF: Radio frequency; STK4: Serine/threonine-protein kinase 4; Tn-T: Troponin T; TRAILR2: TNF-related apoptosis inducing ligand-receptor 2; T0: End of the operation; T3: Three hours postoperatively; T20: Twenty hours postoperatively

\section{Acknowledgements}

We are indebted to Dr. Elisabeth Aardal Eriksson for helping with the biochemistry analyses and to research nurse Inger Huljebrant for assistance with data collection.

\section{Authors' contributions}

All the authors have read the journal's policy on conflicts of interest and they have no conflicts of interest to disclose. All authors have read and understand the journal's authorship agreement and have reviewed this manuscript. G.B., M.A.A., and F. V Conceived and designed the study. Patient inclusion and data collection: G.B. and F.V. Blood sample handling and laboratory analyses: H.E., G.B., and F.V. Statistical analyses and data interpretation: All authors. Contributed to the writing of the manuscript: All authors. Agree with the manuscript's results and conclusions: All authors. ICMJE criteria for authorship read and met: All authors.

\section{Funding}

Financial support was received from The Swedish Heart-Lung Foundation, grant number 20160391, and the ALF founding, County Council of Östergötland, Sweden. These entities had no role in the design, analysis, interpretation, or any other aspect of the study. Open access funding provided by Linköping University.

\section{Availability of data and materials}

The complete datasets generated and analyzed during the current study includes clinical data that are not publicly available due to restrictions by Swedish law. They are available from the corresponding author on reasonable request provided that professional secrecy applies.

\section{Ethics approval and consent to participate}

The study was approved by the Regional Ethical Review Board (2012/371-31) and patients were recruited after written, informed consent by the surgeon the day before surgery.

\section{Consent for publication}

Not applicable.

\section{Competing interests}

The authors declare that they have no competing interests.

\section{Author details}

${ }^{1}$ Department of Health, Medicine and Caring Sciences, Linköping University, Department of Thoracic and Vascular Surgery in Östergötland, Linköping, Sweden. ${ }^{2}$ Department of Health, Medicine and Caring Sciences, Linköping University, Department of Clinical Physiology in Linköping, Linköping, Sweden. ${ }^{3}$ Division of Clinical Chemistry, Department of Biomedical and Clinical Sciences, Linköping University, Linköping, Sweden. ${ }^{4}$ Department of Biomedical and Clinical Sciences, Linköping University, Division of Inflammation and Infection, Linköping, Sweden. ${ }^{5}$ Department of Cardiology in Linköping, and Department of Health, Medicine and Caring Sciences, Linköping University, Linköping, Sweden.
Received: 11 May 2020 Accepted: 6 July 2020

Published online: 13 July 2020

\section{References}

1. Stulak JM, Suri RM, Burkhart HM, Daly RC, Dearani JA, Greason KL, Joyce LD, Park SJ, Schaff HV. Surgical ablation for atrial fibrillation for two decades: are the results of new techniques equivalent to the Cox maze III procedure? J Thorac Cardiovasc Surg. 2014;147(5):1478-86.

2. Xu J, Luc JG, Phan K. Atrial fibrillation: review of current treatment strategies. J Thorac Dis. 2016;8(9):E886-900.

3. Badhwar V, Rankin JS, Damiano RJ Jr, Gillinov AM, Bakaeen FG, Edgerton JR Philpott JM, McCarthy PM, Bolling SF, Roberts HG, et al. The Society of Thoracic Surgeons 2017 clinical practice guidelines for the surgical treatment of atrial fibrillation. Ann Thorac Surg. 2017;103(1):329-41.

4. Chu KF, Dupuy DE. Thermal ablation of tumours: biological mechanisms and advances in therapy. Nat Rev CancerNat Rev Cancer. 2014;14(3): 199-208.

5. Avitall B, Kalinski A. Cryotherapy of cardiac arrhythmia: from basic science to the bedside. Heart Rhythm. 2015;12(10):2195-203.

6. Gage AA, Baust JM, Baust JG. Experimental cryosurgery investigations in vivo. Cryobiology. 2009;59(3):229-43.

7. Zhang WR, Garg AX, Coca SG, Devereaux PJ, Eikelboom J, Kavsak P, McArthur E, Thiessen-Philbrook H, Shortt C, Shlipak M, et al. Plasma IL-6 and IL-10 concentrations predict AKI and long-term mortality in adults after cardiac Surgery. J Am Soc Nephrol. 2015;26(12):3123-32.

8. Luan Y, Guo Y, Li S, Yu B, Zhu S, Li S, Li N, Tian Z, Peng C, Cheng J, et al. Interleukin-18 among atrial fibrillation patients in the absence of structural heart disease. Europace. 2010;12(12):1713-8.

9. Zhang M, Zhang L, Hu J, Lin J, Wang T, Duan Y, Man W, Feng J, Sun L, Jia H, et al. MST1 coordinately regulates autophagy and apoptosis in diabetic cardiomyopathy in mice. Diabetologia. 2016;59(11):2435-47.

10. Wang $X$, Song $Q$. Mst1 regulates post-infarction cardiac injury through the JNK-Drp1-mitochondrial fission pathway. Cell Mol Biol Lett. 2018;23:21.

11. Pawlinski R, Tencati M, Hampton CR, Shishido T, Bullard TA, Casey LM, Andrade-Gordon P, Kotzsch M, Spring D, Luther T, et al. Protease-activated receptor-1 contributes to cardiac remodeling and hypertrophy. Circulation. 2007:116(20):2298-306

12. Batulan Z, Pulakazhi Venu VK, Li Y, Koumbadinga G, Alvarez-Olmedo DG, Shi C, O'Brien ER, et al. Extracellular Release and Signaling by Heat Shock Protein 27: Role in Modifying Vascular Inflammation. Front Immunol. 2016:7:285.

13. Jin C, Cleveland JC, Ao L, Li J, Zeng Q, Fullerton DA, Meng X. Human myocardium releases heat shock protein 27 (HSP27) after global ischemia: the proinflammatory effect of extracellular HSP27 through toll-like receptor (TLR)-2 and TLR4. Mol Med. 2014;20:280-9.

14. Vander Heide RS. Increased expression of HSP27 protects canine myocytes from simulated ischemia-reperfusion injury. Am J Physiol Heart Circ Physiol. 2002;282(3):H935-41.

15. Skau E, Henriksen E, Wagner P, Hedberg P, Siegbahn A, Leppert J. GDF-15 and TRAIL-R2 are powerful predictors of long-term mortality in patients with acute myocardial infarction. Eur J Prev Cardiol. 2017;24(15):1576-83.

16. Cox JL. A brief overview of surgery for atrial fibrillation. Ann Cardiothorac Surg. 2014;3(1):80-8.

17. Swedish Arrhythmia Surgery G, Ahlsson A, Jideus L, Albage A, Kallner G Holmgren A, Boano G, Hermansson U, Kimblad PO, Schersten H, et al. A Swedish consensus on the surgical treatment of concomitant atrial fibrillation. Scand Cardiovasc J. 2012;46(4):212-8.

18. Cox JL, Churyla A, Malaisrie SC, Kruse J, Pham DT, Kislitsina ON, MCCarthy PM. When is a maze procedure a maze procedure? Can J Cardiol. 2018; 34(11):1482-91.

19. Benussi S, Galanti A, Nascimbene S, Fumero A, Dorigo E, Zerbi V, Cioni M, Alfieri O. Complete right atrial ablation with bipolar radiofrequency. Ann Thorac Surg. 2009:87(5):1573-6.

20. Benussi S, Nascimbene S, Galanti A, Fumero A, Dorigo E, Zerbi V, Cioni M, Alfieri O. Complete left atrial ablation with bipolar radiofrequency. Eur J Cardiothorac Surg. 2008;33(4):590-5.

21. Dahlin LG, Kagedal B, Nylander E, Olin C, Rutberg H, Svedjeholm R. Early identification of permanent myocardial damage after coronary surgery is aided by repeated measurements of CK-MB. Scand Cardiovasc J. 2002;36(1): $35-40$. 
22. Oswald H, Gardiwal A, Lissel C, Yu H, Klein G. Difference in humoral biomarkers for myocardial injury and inflammation in radiofrequency ablation versus cryoablation. Pacing Clin Electrophysiol. 2007;30(7):885-90.

23. Malmborg H, Christersson C, Lonnerholm S, Blomstrom-Lundqvist C. Comparison of effects on coagulation and inflammatory markers using a duty-cycled bipolar and unipolar radiofrequency pulmonary vein ablation catheter vs. a cryoballoon catheter for pulmonary vein isolation. Europace. 2013;15(6):798-804.

24. Schmidt M, Marschang H, Clifford S, Harald R, Guido R, Oliver T, Johannes B, Daccarett $\mathrm{M}$. Trends in inflammatory biomarkers during atrial fibrillation ablation across different catheter ablation strategies. Int J Cardiol. 2012; 158(1):33-8

25. Zeng Q, Li X, Xu G. Evaluation of myocardial injury induced by different ablation approaches (radiofrequency ablation versus cryoablation) in atrial flutter patients: a meta-analysis. Biosci Rep. 2019;39(5):BSR20182251.

26. Wojcik M, Janin S, Neumann T, Kuniss M, Berkowitsch A, Erkapic D, Zaltsberg S, Madlener K, Wysokiński A, Hamm CW, et al. Which standard biomarkers are useful for the evaluation of myocardial injury after pulmonary vein isolation with cryoballoon? Kardiol Pol. 2011;69(11):1151-5.

27. Haines DE, Whayne JG, Walker J, Nath S, Bruns DE. The effect of radiofrequency catheter ablation on myocardial creatine kinase activity. J Cardiovasc Electrophysiol. 1995;6(2):79-88,

28. Manolis AS, Vassilikos V, Maounis T, Melita-Manolis H, Psarros L, Haliasos A, Cokkinos D. Detection of myocardial injury during radiofrequency catheter ablation by measuring serum cardiac troponin I levels: procedural correlates. J Am Coll Cardiol. 1999;34(4):1099-105.

29. Yamashita T, Sekiguchi A, Iwasaki YK, Date T, Sagara K, Tanabe H, Suma H, Sawada H, Aizawa T. Recruitment of immune cells across atrial endocardium in human atrial fibrillation. Circ J. 2010;74:262-70

30. Osada S, Imai H, Tomita H, Tokuyama Y, Okumura N, Matsuhashi N, Sakashita F, Nonaka K. Serum cytokine levels in response to hepatic cryoablation. J Surg Oncol. 2007;95(6):491-8.

31. Jansen MC, van Hillegersberg R, Schoots IG, Levi M, Beek JF, Crezee H, van Gulik TM. Cryoablation induces greater inflammatory and coagulative responses than radiofrequency ablation or laser induced thermotherapy in a rat liver model. Surgery. 2010;147(5):686-95.

32. Herrera Siklody C, Arentz T, Minners J, Jesel L, Stratz C, Valina CM, Weber R, Kalusche D, Toti F, Morel O, Trenk D. Cellular damage, platelet activation, and inflammatory response after pulmonary vein isolation: a randomized study comparing radiofrequency ablation with cryoablation. Heart Rhythm. 2012;9(2):189-96.

33. Erinjeri JP, Clark TW. Cryoablation: mechanism of action and devices. J Vasc Interv Radiol. 2010;21(8 Suppl):S187-91.

34. Teringova E, Tousek P. Apoptosis in ischemic heart disease. J Transl Med. 2017;15(1):87.

35. LeBlanc HN, Ashkenazi A. Apo2L/TRAlL and its death and decoy receptors. Cell Death Differ. 2003;10(1):66-75.

36. Shepard BD, Badley AD. The biology of TRAlL and the role of TRAIL-based therapeutics in infectious diseases. Antiinfect Agents Med Chem. 2009;8(2): 87-101.

37. Tamada T, Shinmi D, Ikeda M, Yonezawa Y, Kataoka S, Kuroki R, Mori E, Motoki K. TRAlL-R2 Superoligomerization induced by human monoclonal agonistic antibody KMTR2. Sci Rep. 2015;5:17936.

38. Boano G, Astrom Aneq M, Kemppi J, Vanky F. Cox-maze IV cryoablation and postoperative heart failure in mitral valve surgery patients. Scand Cardiovasc J. 2017;51(1):15-20.

\section{Publisher's Note}

Springer Nature remains neutral with regard to jurisdictional claims in published maps and institutional affiliations.

Ready to submit your research? Choose BMC and benefit from:

- fast, convenient online submission

- thorough peer review by experienced researchers in your field

- rapid publication on acceptance

- support for research data, including large and complex data types

- gold Open Access which fosters wider collaboration and increased citations

- maximum visibility for your research: over $100 \mathrm{M}$ website views per year

At BMC, research is always in progress.

Learn more biomedcentral.com/submissions 